\title{
ARTE Y COMPROMISO SOCIAL: LA OBRA DEL PINTOR FRANCISCO CUADRADO
}

\author{
POR JOSÉ RAYA TÉLLEZ
}

\begin{abstract}
El presente artículo intenta ofrecer una visión de conjunto de la obra del pintor Francisco Cuadrado, cualificado representante del llamado "realismo social", dentro de la escuela figurativa sevillana. En este proceso estudiamos los pasos a través de los cuales se plasma su producción estética, mediante el análisis y comentario de sus obras más relevantes.
\end{abstract}

The prsent article attempts to offer a well-rounded view in the evolution of the painter Francisco Cuadrado's work, eminent representative of the so-called 'social realism', within the figurative shool of Seville. In that process we study the steps through which his aesthetic production is drawn out by means of the analysis and commentary of some of his most relevant works.

Casi constituye una obviedad venir a recordar que el estudio de la producción plástica más reciente en nuestra ciudad ha suscitado un escaso interés académico, de modo que consistentes aportaciones individuales andan necesitadas de estudios pormenorizados que vengan a clarificar su fisonomía y a ratificar, o no, informaciones poco contrastadas ${ }^{1}$.

Uno de estos casos lo constituye la contribución creativa del pintor Francisco Cuadrado Lagares, cuya obra plástica ha despertado nuestro interés por dos razones fundamentales. En primer lugar, por constituir un caso ejemplar de lo que se ha dado en llamar "arte comprometido", de sus aciertos y limitaciones, y del proceso de transformación que hubo de sufrir para adaptarse a un mundo de más que problemáticas certezas. En un segundo término, por su importante contribución a la eclosión

1. Lo que no resta un ápice de interés a los meritorios estudios de conjunto de A. Bonet Correa, "Sevilla: panorama artístico del siglo XX", en Los Andaluces, edit. Istmo, Madrid, 1980, pp. 569-593; Ana Guash, 40 años de pintura en Sevilla (1940-1980), Diputación Provincial de Sevilla, Sevilla, 1981; y Fernando Martín Martín, "Pintura contemporánea", en Sevilla y su provincia, Edit. Gever, vol. V, Sevilla, 1993. 
de una nueva figuración en los albores de los 60 , que venía a poner en cuestión el edulcorado y bienpensante realismo de la inmediata posguerra.

Queremos dejar constancia de que las fuentes para el estudio de nuestro pintor no son excesivamente abundantes. Las de carácter bibliográfico se reducen, prácticamente, a los dos catálogos de su obra ${ }^{2}$, y las de tipo hemerográfico no son tampoco particularmente profusas, lo que cabe atribuir en gran medida a que el artista -como el resto de los integrantes del grupo de Estampa Popular, del que formó parte- buscó en todo momento canales alternativos de exhibición, lo que le valió el ser ignorado por determinados medios periodísticos a los que, por lo demás, tampoco gustaba en exceso el violento expresionismo y la agresividad temática del pintor, tan opuesta al costumbrismo escapista de la Sevilla oficial. Por esta circunstancia, las entrevistas con el pintor nos han sido de suma utilidad, no sólo en la reconstrucción de su trayectoria vital sino, muy especialmente, en el análisis de su obra.

\section{PERFIL BIOGRAFICO Y AMBIENTE ARTISTICO.}

La semblanza biográfica de un artista nos parece un componente obligado en trabajos de esta naturaleza, por el carácter decisivo que la trayectoria vital de cada autor ha de dejar necesariamente en su obra. En el caso de Cuadrado la pertinencia de este apartado se hace todavía más patente, si cabe, habida cuenta de la extraordinaria imbricación que siempre se produce entre su compromiso político y su producción plástica. No obstante, dados los límites de esta colaboración, procuraremos no ser excesivamente prolijos.

Francisco Cuadrado Lagares nace en Sevilla en 1939, en el seno de una familia humilde, ya que su madre era costurera y su padre trabajador de la Fábrica de Artillería. En 1950 ingresa en la Escuela de Artes y Oficios de la Ronda de Capuchinos, pasando más tarde por las de la calle Zaragoza y por el Pabellón de Chile, alternando estas enseñanzas con las que recibe en el Ateneo de Sevilla, donde encuentra un primer círculo de amigos, entre los que cabe citar a José Luís Pajuelo, Roberto Reina, Justo Girón y García Gómez.

En 1957 ingresa en la Escuela de Bellas Artes, donde cultiva la amistad de Cristobal Aguilar y Francisco Cortijo, por cuya influencia abandona los estudios en el curso tercero. De este período recuerda con especial agrado la figura de Don Miguel Pérez Aguilera, con el que, no obstante, mantuvo alguna que otra diferencia.

En 1959 viaja a París en compañía de Cristobal y, junto con Cortijo, que ya se encontraba allí, ponen las bases de lo que sería el Grupo Sevilla de Estampa Popular. Dos años más tarde, en 1961, el colectivo organiza su primera exposición de grabados en la galería Velazquez.

2. A. A. V. V., Paco Cuadrado, Obra Cultural El Monte, Sevilla, 1990; y A. A. V. V., Paco Cuadrado. La figuración desde el realismo social 1955 - 1993, Fundación El Monte-Ayuntamiento de Dos Hermanas, Dos Hermanas, 1993. 
En 1964 el pintor es detenido debido a su militancia política y pasa seis meses en la prisión de Ranilla. No obstante, al año siguiente celebra varias exposiciones: sala Vayreda de Barcelona, galería la Pasarela de Sevilla y Griffe-Scoda de Madrid. Pero la libertad dura poco porque en 1969 Cuadrado ingresa de nuevo en prisión, esta vez con su esposa Mari Paz. En esta ocasión la experiencia carcelaria dura hasta 1972, año en que el pintor se instala en San Juan de Aznalfarache, reiniciando su tarea como grabador y pintor en una nueva etapa en la que la ayuda de su colega Rolando Campos juega un papel muy relevante.

Desde entonces, y hasta 1978, Cuadrado dedica la mayor parte de su actividad a exponer y difundir su labor artística por centros populares y asociaciones culturales, culminando este período con su participación en la Semana de Cultura Andaluza, celebrada en París en el mencionado año.

A partir de entonces, el pintor pasa por una etapa muy crítica que se concreta en un cuestionamiento de toda su obra anterior, al tiempo que, abandonada la militancia política, se acerca a la pintura de forma más libre y desprejuiciada, a lo que no es ajeno tanto su mejor conocimiento de la literatura artística más reciente como su acercamiento más profundo a los maestros del postimpresionismo.

De esta etapa traumática el artista consigue salir a través de tres hitos sucesivos: la exposición retrospectiva de 1990, una suerte de sinopsis plástica que le reconcilia con la obra pasada; la que, con motivo de los eventos del 92, se organiza en el monasterio de San Clemente, que le ratifica en la apreciación de que su obra posee un nivel de dignidad nada despreciable; $y$, por último, su puesta en contacto con la naturaleza a través del pueblo onubense de Fuenteheridos, en 1993. A partir de ese momento nuestro pintor asume sin complejos su obra pasada e inicia una nueva etapa cuyos derroteros se cree incapaz de prever, cosa que, por lo demás, tampoco le preocupa en exceso.

En lo tocante al ambiente artístico en el que surge la obra de Cuadrado a finales de los 50 cabría llegar, parafraseando a Ana Guash ${ }^{3}$, a las siguientes conclusiones:

a) Rechazo oficial de la más leve modernidad en aras de la sobrevaloración del oficio y del virtuosismo técnico, lo que, por cierto, concuerda con los deseos del régimen político de enlazar con un pasado precapitalista que idealiza la actividad corporativa y artesanal.

b) Evidente atraso de la ciudad respecto a otros centros culturales del país que, por estas fechas, se estaban incorporando a corrientes artísticas más renovadoras, tales como el informalismo o la abstracción analítica.

c) De modo que el máximo de modernidad aportado por la ciudad en estos años no iba más allá de una figuración que oscilaba entre un seudocubismo de resabios impresionistas y un expresionismo interpretado con cierta originalidad.

3. Ana Guash, ob. cit., p. 27. 


\section{LA OBRA DE FRANCISCO CUADRADO.}

A nuestro modo de ver, en la evolución de su obra son discernibles tres períodos claramente diferenciados:

\section{Los años de militancia: 1959-1978.}

Sin duda el período más dilatado y donde se dan las obras más relevantes -es la época del compromiso político, los años de militancia y del realismo social-, que se plasman esencialmente en su producción como grabador dentro del Grupo Sevilla de Estampa Popular. También se da una importante producción pictórica, injustamente oscurecida por su pertenencia al mencionado colectivo. En uno y otro caso notamos una serie de características que trataremos de esbozar en apretada síntesis.

En primer lugar observamos un claro predominio de la figura humana, imputable no sólo al hecho de que sea un tema con el que el pintor se siente particularmente cómodo, sino también a una derivación de típico humanitarismo socialista, y - cómo no - a una evidente consecuencia del discurso político previo. Por lo general, esta figura humana no es identificable, lo cual no carece de lógica habida cuenta de que el compromiso social del artista le lleva a un esencialismo reñido con cualquier tipo de concreción, que, en su opinión, sólo vendría a banalizar el tema representado. De ahí que, pese a esta ubicuidad de la figura humana, el retrato no sea abundante en la producción de estos años.

De entre esta figuras sobresalen especialmente las de ancianos y niños, probablemente las víctimas más inermes del modelo social que el pintor pretende denostar. Unos y otros nos hablan de las lacras de un sistema inhumano y nos demandan el compromiso de lucha y la respuesta solidaria.

Un segundo rasgo de la producción de estos años sería la escasa presencia del mundo objetual, esto es, la casi ausencia de aquellos enseres de la vida cotidiana que suelen acompañar a la figura humana, contribuyendo a su localización en el espacio. Las figuras aparecen solas, aisladas, sobre fondos neutros, desprovistas de la presencia de objetos que puedan restar relevancia a su insoslayable existencia. Como ya se podrá suponer, todo ello tiene bastante que ver con el esencialismo militante al que antes hacíamos alusión, y, en definitiva, con el discurso políticosocial del que se parte, cuyo riesgo de trivialización se pretende evitar mediante esa extremada sobriedad en la alusión del entorno.

En tercer lugar habría que aludir al fuerte contenido social, derivado de la poderosa presencia del mencionado discurso, referido casi siempre a una realidad rural en la que el pintor trata de representar los agobios de las clases trabajadoras, el lacerante problema del paro, el drama de la emigración y, en suma, el abandono de los más débiles. Esta realidad social es, en la inmensa mayoría de los casos, una 
realidad campesina, aquella con la que el pintor, por su inmediatez, se siente más familiarizado.

En ningun momento esta realidad social es contemplada de forma aséptica y neutral - habida cuenta del fuerte compromiso político del pintor -, por lo que la obra de estos años posee un acentuado carácter militante y reivindicativo, de modo que, con frecuencia, el cuadro o la estampa adquieren un valor instrumental, se consideran una forma de lucha al servicio de la consecución de una realidad social más justa. Por esta razón, los personajes que pueblan su obra aparecen imbuidos de una fuerte dignidad que les impide caer en la resignación, puesto que, después de todo, constituyen el material humano que habrá de alumbrar el nuevo mundo.

Por tratarse, además, de la representación de una humanidad doliente, la pintura y el grabado de estos años apareçen dotados de un fuerte carácter expresionista, cuyo objetivo consiste esencialmente en buscar la respuesta solidaria en el espectador, en provocar una complicidad cordial que, a veces, no consigue evitar la caida en lo sensiblero ni en la repetición del arquetipo fácil, riesgo que, por lo demás, tampoco logró soslayar el resto de los integrantes de Estampa Popular.

Otro rasgo muy importante en esta primera etapa es el ingenuismo y hasta primitivismo de que hace gala el pintor, por otra parte tan frecuente en la pintura de nuestro siglo. En principio cabría relacionar esta característica con la propia ingenuidad del pintor, con su falta de afectación y con lo rudimentario de su cultura artística, pero se nos antoja que también tiene mucho que ver con un esencialismo que lleva al artista a detenerse sólo en lo estrictamente necesario para la compresión del mensaje. Este ingenuismo no sólo concierne a aspectos como la iconografía y la composición sino que, incluso, atañe a la misma técnica empleada. En cualquier caso, se habrá de convenir en que es ahora, a esta altura de nuestra exposición, cuando adquieren sentido las palabras del historiador del arte Drew Egbert:

"En la historia occidental, el primitivismo cultural ha sido a menudo una forma adoptada por el comunismo y el igualitarismo, con sus consiguientes efectos sobre las artes." 4

Para concluir, desearíamos hacer una brevísima referencia a los elementos plásticos, constatando, en primer lugar, el absoluto predominio del dibujo, lo que hay que adjudicar tanto a la formación académica del pintor como a la rotundidad que pretende conferir a sus personajes. Esto es aplicable tanto a su obra gráfica como a la pintura, afectada en gran medida por el carácter absorbente que para el artista posee el trabajo como grabador en estos momentos. Ello explicaría también su muy atemperado cromatismo.

No obstante, hay que tener presente que este primer período del realismo social es muy dilatado y es ello lo que explica el que se detecten sensibles diferencias entre las pinturas y grabados de los comienzos de la etapa y los del momento final. Y en

4. Donal Drew Egbert, El Arte y la izquierda en Europa. De la Revolución Francesa a mayo de 1968, Edit. Gustavo Gili, Barcelona, 1981, p. 49. 
este sentido la fecha de 1972, la de su segunda salida de la cárcel, nos parece verdaderamente significativa, porque a partir de ese momento su producción comienza a presentar cambios notables que anuncian la etapa siguiente. La pérdida de la influencia de Francisco Cortijo, la vuelta a su Sevilla natal y su inminente paternidad, estarían en el origen de este cambio.

Por razones de espacio vamos a referimos sólo de pasada a la labor de Cuadrado como grabador, en su papel de integrante del Grupo Sevilla de Estampa Popular ${ }^{5}$, dedicando mayor atención a su labor pictórica, injustamente preterida en favor de su producción gráfica.

Como es sabido, el Grupo Sevilla de Estampa Popular, integrado originariamente por los artistas Francisco Cortijo, Francisco Cuadrado y Cristobal Aguilar, se fragua en París en 1960, y aunque su crecimiento no fue tan multitudinario como sus mentores habían pensado, en los meses de enero y febrero de 1961 celebró su primera exposición colectiva en la Galería Velazquez ${ }^{6}$. Sin embargo, pronto el grupo entra en crisis y, pese a un intento de refundación, se disuelve en 1964, con lo que a partir de ese momento sólo quedará la labor de francotirador de Cuadrado, cuyo fuerte compromiso político le lleva a mantener durante mucho tiempo - a nuestro modo de ver, más de lo necesario - los postulados y aspiraciones iniciales del colectivo, pese a las limitaciones que le imponían sus persistentes encontronazos con el aparato represivo de la dictadura.

Los grabados de estos años acusan un predominio absoluto de la figura humana como demanda lógicamente una temática social y reivindicativa. Los personajes se suelen presentar plasmados con arreglo a un estereotipo (fig. 1) que debe mucho a la temática de José Ortega, Antonio Quirós y, sobre todo, Francisco Cortijo. Son figuras fuertemente distorsionados por un acentuado expresionismo que tiene por objeto hacer más evidente la injusticia social, lo que se consigue a través de una acentuada carga subjetiva y sentimental. Su aspecto suele ser hierático, su continente famélico y desnutrido, la mirada a veces torva, otras acusadora; pero, en cualquier caso, siempre se nos presentan cargados de entereza y dignidad. No obstante, este esencialismo, este representar la figura humana según ideas preconcebidas, esta reiteración de los motivos y este modo de expresar la realidad con escasísimas alusiones al entorno, nos sumergen en un mundo de intemporalidad que, por seco y desmañado, nos llega a producir cierto cansancio. $Y$ ello sucede porque, a veces, se cae en el arquetipo y en la figura genérica alejada de la realidad social, lo que no implica, en modo alguno, que lo descrito no sea auténtico, sino que:

"... el procedimiento escogido para plasmarla tiene que ver más con el emblema y el símbolo, con el estereotipo, que con el realismo, más con la

5. Vide Virginia Marqués Ferrer, Estampa Popular: el Grupo Sevilla, memoria de licenciatura inédita, Sevilla, 1987.

6. Vide Manuel Lorente, "El Grupo Sevilla, muestra de la vibración artística de la ciudad", diario PUEBLO, 7-IV-1961. 
generalidad que con la concreción, más con la exaltación sentimental que con la información efectiva." ${ }^{7}$

Por lo que se refiere a su obra pictórica durante este período, hemos de decir que ha sido injustamente postergada. Y ello es así porque el artista ha sido estudiado y valorado sobre todo en función de su participación en la experiencia de Estampa Popular, esto es, en función de su valor como grabador, quedando arbitrariamente oscurecida su tarea como pintor. Sin duda alguna a ello ha contribuido decisivamente la mayor difusión de su obra gráfica, lo que, en gran medida, viene explicado por su baratura y manejabilidad. En suma, sus grabados eran mucho más accesibles al gran público que sus cuadros, destinados a una clientela bastante más restringida. Por otro lado, hay que tener muy presente que Cuadrado, por el peso de su militancia política y el valor instrumental que siempre concedió a su obra, permaneció durante mucho tiempo fiel a los presupuestos ideológicos del grupo, incluso cuando éste ya se había disuelto, lo que desde luego no facilitó el conocimiento de su obra pictórica.

De forma similar a lo que sucedía con el grabado podemos decir que en las pinturas de los sesenta se recurre a un acentuado expresionismo, que tiene en el alargamiento arbitrario de los personajes uno de los recursos más socorridos. Este alargamiento es tributario de un predominio absoluto de la línea y el dibujo, sin duda requerido por el deseo del autor de conferir rotundidad a unos personajes que nos hablan de injusticia, abandono y marginación. Ocioso es decir que se insiste, a veces hasta la reiteración, en el mensaje miserabilista y populista que en su momento comentamos para los grabados.

Estos personajes aparecen localizados en unos fondos neutros e indeterminados, en los que cualquier referencia al entorno posee un carácter sumario y casi simbólico, como si el artista quisiera enfrentarnos sin posibilidad de escape a la tremenda realidad que pregonan. Por esta razón, los fondos paisajísticos están casi ausentes.

Ya se comprenderá que por, idénticas razones de austeridad y economía de medios, - sin duda alguna relacionados con la despótica presencia del mensaje doctrinario - la gama cromática de estas obras se nos aparece bastante atenuada, con un predominio casi absoluto de los ocres-terrosos, verdes, azules y rojos a veces distribuidos en amplias manchas de color en las que no es posible percibir una gran variedad de tonos ni matices.

De nuevo la figura humana posee una ubícua presencia, subordinada en la mayoría de los casos a transmitir un mensaje de alto contenido social y reivindicativo. Para ejemplificar este aserto vamos a referirnos a dos de sus obras más celebradas. En la primera de ellas, "Pan y trabajo" (fig. 2), se nos presentan tres muchachos, dos chicos y una chica, en alusión a la típica organización ternaria de las células comunistas campesinas. Los muchachos del centro y de la izquierda son en realidad la misma persona, en este caso el jóven que solía servir de modelo a Francisco

7. Valeriano Bozal y otros, El grabado en España (siglos XIX y XX), Espasa Calpe, Madrid, 1988, p. 759 
Cortijo, del que se toman también los estereotipos. El personaje del centro parece ser el líder del grupo y se dirige hacia el espectador tratando de comunicarle algo, mientras sus compañeros le miran expectantes. Repárese en la acentuada simetría del cuadro, subrayada por la colocación de las figuras laterales, la dirección de las miradas, los instrumentos de labranza esgrimidos casi como armas y la postura de las manos de la figura central. Esta simetría no es, ni mucho menos, casual, sino premeditadamente buscada al objeto de conferir al cuadro un aura casi sacral, un halo de misticismo que, por supuesto, tiene mucho que ver con la dignidad y el empaque que se pretende otorgar a la escena. A todo ello no es ajeno, probablemente, la extraordinaria admiración del artista por la pintura flamenca, cuya influencia es más que perceptible en algunos de los cuadros de estos años. De estos pintores le atraían toda una serie de virtudes que él pretendía hacer suyas, especialmente la pulcritud, el bien hacer, el oficio, en suma, el carácter artesanal de su pintura. Nótese, además, que tanto el soporte utilizado - la tabla - como los fondos dorados de algunos de sus cuadros, nos remiten también a la práctica habitual de los maestros medievales. Hay que tener presente, en fin, que este carácter místico, sacral y hierático no era nuevo en la pintura de la posguerra. Rafael Zabaleta, uno de los mentores iconográficos de Estampa Popular, ya había discurrido por estos derroteros, como pudo observar Valeriano Bozal:

"La sensación que producen muchas de las imágenes de Zabaleta es la de un retablo que no pertenece al espectacular dinamismo del barroco sino a la intemporalidad sagrada del románico. Hay algo de medieval en estos cuadros clasicistas, cuidadosamente compuestos, simétricos. Lo medieval es la ausencia del tiempo y la intensidad del realismo, es decir, de la verosimilitud." ${ }^{8}$

Por lo demás, no cabe duda de que la intensa espiritualidad que rezuman los personajes viene acentuada por el alargamiento arbitrario de los mismos, basado en un predominio absoluto de la línea. Estamos ante una forma -popular, si se quiere de manierismo, a la que ayuda fuertemente la compresión del espacio en el que las figuras se aprietan. Sin embargo, como ya tuvo oportunidad de apuntar Virginia Marqués para el grabado ${ }^{9}$, pese al patetismo de las figuras, éstas llegan a afirmar su dignidad como personas que no pierden la esperanza, convencidas como lo están del triunfo ineluctable del evangelio igualitario que predican, aquí aludido por las palabras que el dirigente campesino dedica al espectador.

En "Las costureras" (fig. 3), es difícil establecer dónde termina la obra de contenido social y comienza a aparecer el cuadro de tipo costumbrista, suponiendo que sea legítimo establecer esta distinción. Indudablemente se trata de un tema de época, de un modesto homenaje a las mujeres que por los años 50 se ganaban la vida cosiendo para la calle trajes, manteles, ajuares, etc, realidad que Cuadrado debía

8. Valeriano Bozal, Pintura y escultura españolas del siglo XX (1939-1990), Espasa Calpe, Madrid, 1992, p. 178.

9. Virginia Marqués Ferrer, ob. cit.,p.91 
conocer muy bien, puesto que su madre se había dedicado a esta actividad con el fin de engrosar el magro presupuesto familiar.

En una breve descripción del cuadro se observa que nos encontramos en el interior de un obrador - ¿acaso estamos ante una cita velazqueña? - en el que tres muchachas, en realidad la mujer del pintor tomada desde distintos ángulos, se afanan en su tarea de costura, mientras, a la izquierda, son contempladas por una anciana, y, a la derecha, por dos niños que se asoman a un balcón. En el centro, en la parte superior, el espacio se prolonga a través de líneas de fuga muy pronunciadas hacia lo que parece ser un patio de vecinos. La composición, típicamente tectónica, aparece muy estabilizada por el predominio de horizontales y verticales, que nos darían un cuadro muy sosegado si no fuera por el movimiento febril que trasmiten las manos de las muchachas.

Pues bien, si por un lado hemos de reconocer que en este cuadro se dan los elementos que nos permiten hablar de costumbrismo, en la medida en que se levanta acta de actividades, formas de vida y enseres que se encuentran en trance de desaparecer - como la costura para la calle, la silla de enea o la puerta de cuarterones -, por otro tendremos que convenir en que estamos ante una obra que tiene bastante poco que ver con el edulcorado costumbrismo de tradición sevillana, como se echa de ver en el agobio con que las operarias se aplican a su trabajo, o en la atmósfera de desasosiego y absurdo que crean las puertas y pasillos que se vislumbran al fondo. En suma, parece como si la protesta social, inherente a toda su obra, atemperase los componentes tranquilizadores y bienpensantes de la estética costumbrista.

\section{La vuelta hacia el entorno y la recuperación de la pintura: 1978 - 1990.}

El año de 1978 marca una cesura importante en la vida y la obra de nuestro pintor, a lo que no es ajeno su viaje a París ese mismo año. El arquitecto Víctor Pérez Escolano, amigo personal del pintor, ha sabido expresar con bastante acierto el valor de este reencuentro:

"El viaje a París de 1978 resultará decisivo. París ya no es sólo una meca de la libertad, un centro de adoctrinamiento político; París recobra sus valores estéticos, sus museos se abren a los ojos de Cuadrado que decide reconocerse en lo que es sobre todas las cosas: pintor.

Todo el universo de la pintura contemporánea a partir del postimpresionismo adquiere un valor extraordinario, y las visiones del mundo real aportadas por Matisse o Morandi, explotan en la sensibilidad del artista que vive una especie de nueva adolescencia." 10

10. Víctor Pérez Escolano, "Los ochenta de Paco Cuadrado", en Paco Cuadrado (Cat.), Sevilla 1990. 
Y fue posiblemente este primer encuentro desprejuiciado con la pintura el que debió llevar al artista a la conclusión de que era posible crear belleza sin que la obra de arte tuviera que estar condicionada por ningún discurso previo, y de que el cuadro no necesitaba en absoluto de justificaciones extraartísticas.

No obstante, aún reconociendo la importancia del viaje a París en orden al "descubrimiento" de la pintura y a su reconciliación con el concepto del arte por el arte, hay que tener presentes otras tres circunstancias:

a) Que ya en los últimos años de la fase precedente, la obra de Cuadrado comienza a hacerse más sensible a las sugestiones del color, de modo que asistimos a una cierta relativización de los contenidos narrativos.

b) Que tan importante como el mencionado viaje para la recuperación de la pintura es el descubrimiento de una literatura artística hasta ese momento desconocida por el pintor, por considerar que la certeza del evangelio comunista le liberaba de tener que plantearse embarazosas preguntas sobre el sentido y fin de la creación plástica.

c) Que la ruptura del compromiso político del artista -que se produce por estos años - le permite salir del gueto social e ideológico en el que hasta ese momento se había movido, abriéndose a otros ámbitos culturales en los que descubre una nueva sensibilidad que, por supuesto, también hay que valorar en el origen del susodicho "descubrimiento" de la pintura. Las tertulias en el estudio del pintor Santiago del Campo constituyen la mejor plasmación de este abandono de la marginación cultural y social a que aludimos.

Conviene apuntar que la renuncia al compromiso político por parte del pintor origina importantes repercusiones en el censo de su obra. El grabado - vehículo fundamental en la tarea de trasmisión de su mensaje comprometido - se hace más raro, y el que subsiste posee un contenido que tiene poco que ver con lo realizado hasta entonces. Ese abandono es el que explica también la menor presencia de la figura humana en la producción de estos años, en aras del abundante cultivo de unos géneros - retrato y paisaje - hasta este momento un tanto preteridos. Uno y otro tendrán mucho que ver con la nueva clientela a la que el pintor se vincula, para el caso del retrato, o con los ejercicios de recreación de los grandes maestros por los que se siente atraido, por lo que atañe al paisaje.

Centrándonos en el primero de estos géneros, hemos de decir que en el período anteriormente estudiado el retrato estaba limitado casi exclusivamente al ámbito familiar del pintor, en la medida en que, trabajando fundamentalmente para una clientela proletaria o pequeñoburguesa, su cultivo hubiese sido de todo punto ruinoso, aparte de que, por estar destinado a un consumo individual, contravenía flagrantemente el marchamo social que pretendía conferir a su obra, en la que debían predominar, por encima de todo, los temas de carácter colectivo, esto es, los que afectasen al mayor número de seres humanos. 
Pero ahora las circunstancias cambian, y el artista, subyugado por la exquisitez, el elitismo cultural, el "savoir faire", en suma, de su nuevo círculo de amistades integrado en gran medida por una burguesía intelectual de cierta ascendencia en Sevilla - se abre a una nueva clientela.

Acaso lo más llamativo de los retratos de esta época sea el intento del pintor por dotarlos de una atmósfera, sumergiendo a los personajes en un ambiente vaporoso y evanescente que, curiosamente, los dota de mayor realidad que a los de antaño, acaso más rotundos éstos por la contundencia del dibujo, pero bastante más irreales por estar ajenos a los matices que establece el ambiente. $Y$ si bien nos sentimos tentados de poner en relación esta difuminación de los contornos y esta inclinación por lo etéreo con el relativismo ideológico en el que el artista se debate por esta época, tampoco conviene olvidar que estos son lo únicos elementos con que cuenta el pintor para incorporar el atractivo, la exquisitez y la elegancia de una determinada burguesía que, acaso consciente de su escasa relevancia social, opta por recluirse en un gueto de melancólica complaciencia. De modo que la captación de ese ambiente nos parece que posee un valor de representación indudable, habida cuenta de que siempre se expresa como plácido y cómodo, aunque carente de toda afectación. En suma, se trataría de una forma como otra cualquiera de afirmar un cierto aristocratismo del espíritu.

En este sentido iría el alargamiento arbitrario al que el artista somete a los personajes. Esta deformación no es nueva, pero entendemos que su motivación es distinta a la que alentó la época del realismo social. Entonces significaba una deformación expresiva que perseguía exacerbar el contenido sentimental y miserabilista. Ahora sólo pretende venir a acentuar el aire elegante y el porte distinguido del retratado.

Muestra de todo lo dicho es el retrato titulado "Marina", (fig. 4), dibujo a lápiz sobre papel en el que Cuadrado nos deja una espléndida semblanza de la pintora Marina Díaz Velazquez, que aquí aparece de pie dirigiendo la mirada hacia la izquierda y con las manos a la espalda. El alargamiento de la figura contribuye a realzar el aura de elegancia que el pintor supo ver en ella y ante la que no es difícil evocar las bellísimas palabras que en una ocasión le dedicara el también pintor Santiago del Campo:

"Como pintora es pintor; como mujer, en cambio, es mujer y mucha aunque batusi, leño requemado y carbón diamantino. Si bellísima y pulida de siglos, de milenios su ingenio afilado y rebosante el aljibe de su verbo." ${ }^{11}$

\section{Reencuentro y asunción del pasado: 1990 - 1994.}

Hacia fines de los 80 el pintor pasa por una profunda crisis que le lleva a negar su producción de los primeros años, por considerarla, con notoria injusticia, populista, panfletaria y absolutamente marginada de las más sugestivas aportaciones de la 
reciente literatura artística. Y este proceso de negación es tan profundo que el artista llega a plantearse seriamente la posibilidad de abandonar la pintura. Si al final no lo hace es porque, a la postre, se produce el reencuentro pacífico con la propia obra, en un proceso plagado de incertidumbre y desánimo, que hoy, visto a cierta distancia, el artista considera se produjo a través de tres hitos sucesivos.

El primero vino dado por la exposición retrospectiva de noviembre de 1990 , en cuyo proceso de selección y montaje el pintor pudo llegar a la conclusión de que el tono general de su obra se mantenía dentro de unos niveles generales de calidad y dignidad bastante aceptables. El éxito de la exposición y las críticas favorables que concitó le ratificaron en la certeza de sus apreciaciones.

La exposición "Pintores de Sevilla 1952 - 1992", celebrada éste último año en el Real Monasterio de San Clemente, le hizo llegar a la conclusión de que la anterior valoración no era producto del narcisismo sino resultado de un análisis serio y ponderado, que, de alguna manera, derivaba también de la inevitable comparación de la propia obra con la del resto de los componentes de la muestra.

Paralelamente a estas dos experiencias, el artista parece ir intuyendo la necesidad de recurrir a una radical soledad que, lejos del tráfago ciudadano, le permita el reencuentro consigo mismo y el inicio de una nueva etapa. Es en este contexto en el que hay que situar su descubrimiento del pueblo onubense de Fuenteheridos, experiencia casi catártica de contacto con la naturaleza que vino a significar, entre otras cosas, una exacerbación de la capacidad de análisis e introspección del pintor, que había de permitir no sólo la definitiva asunción de su pasado, sino la alentadora convicción de que una buena dosis de incertidumbre y de inseguridad en el proceso de creación no tiene por qué ser vivida con dramatismo paralizante. Más aún, que acaso fuera conveniente vivir instalado en ella como único modo de garantizar la autenticidad y validez de la creación plástica. Esto, y no otra cosa, significa la madurez del artista. La certeza de que ya no necesita demostrar ni demostrarse nada para aceptarse como pintor, y la gozosa certidumbre de que si no se es moderno, peor para la modernidad. Y desde esta sosegada perspectiva contempla el artista la evolución de su pintura actual, sin atreverse a vaticinar -porque en realidad tampoco le preocupa- los derroteros por donde haya de discurrir.

No obstante, no desearíamos concluir este trabajo sin aludir, siquiera sea brevemente, a ese afortunado retorno al paisaje representado por sus visiones de Fuenteheridos (fig. 5) que, extrañamente deudoras del mejor Cezanne, nos plasman con rara maestría el color ambiente y la fisonomía austera de los castaños en la estación invernal. Aquí, abandonados los ejercicios retinianos de sus anteriores vistas del Aljarafe, el pintor, como el maestro de Aix, se nos muestra más preocupado por la constitución de estructuras, en una interpretación de la naturaleza que, en algunos ejemplos de la serie, incardina cielo, tierra y árboles en un desbordante torbellino cósmico. 


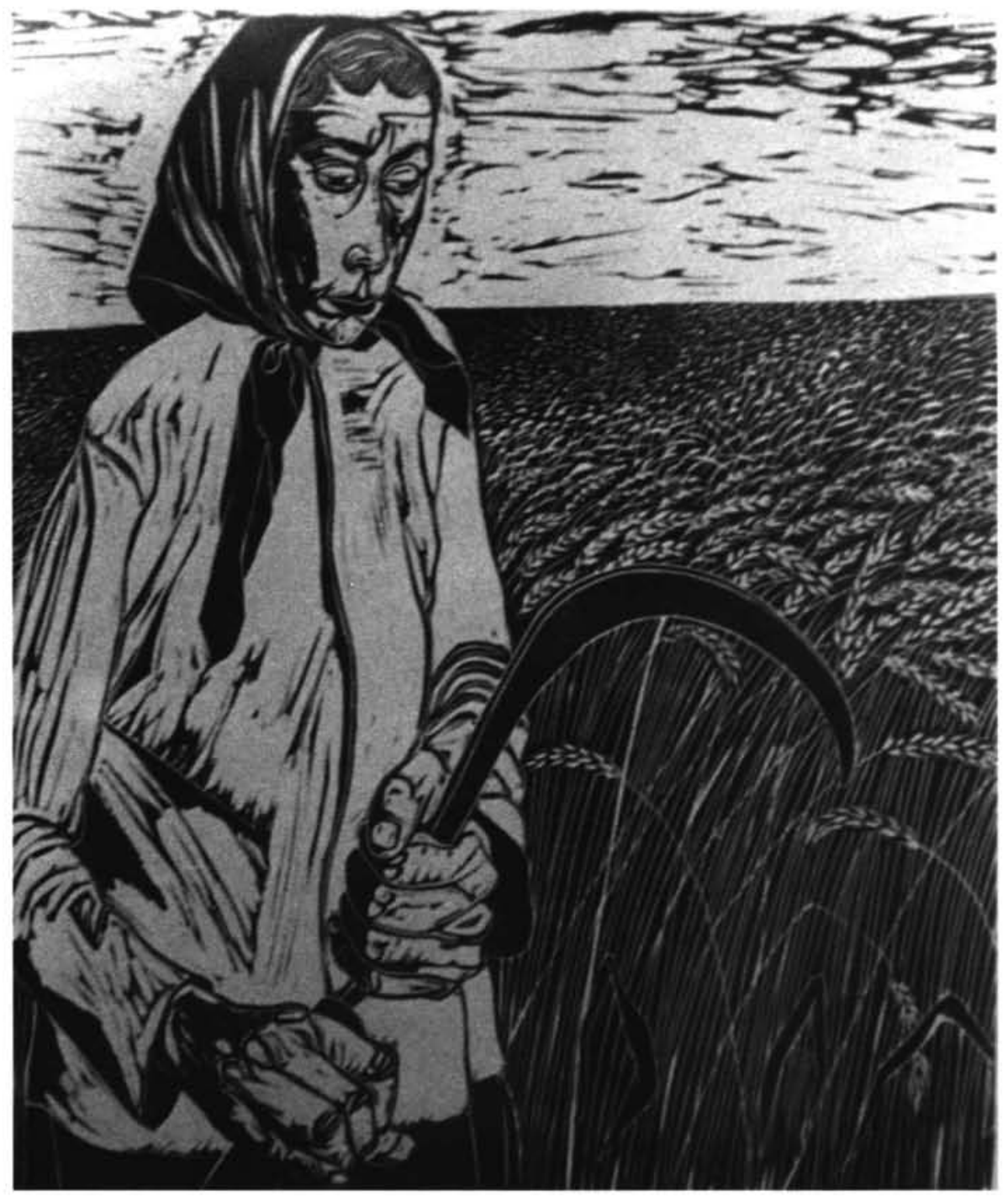

Fig. 1: Campesina. 1960. Linóleo. 25 × 30 cms. 


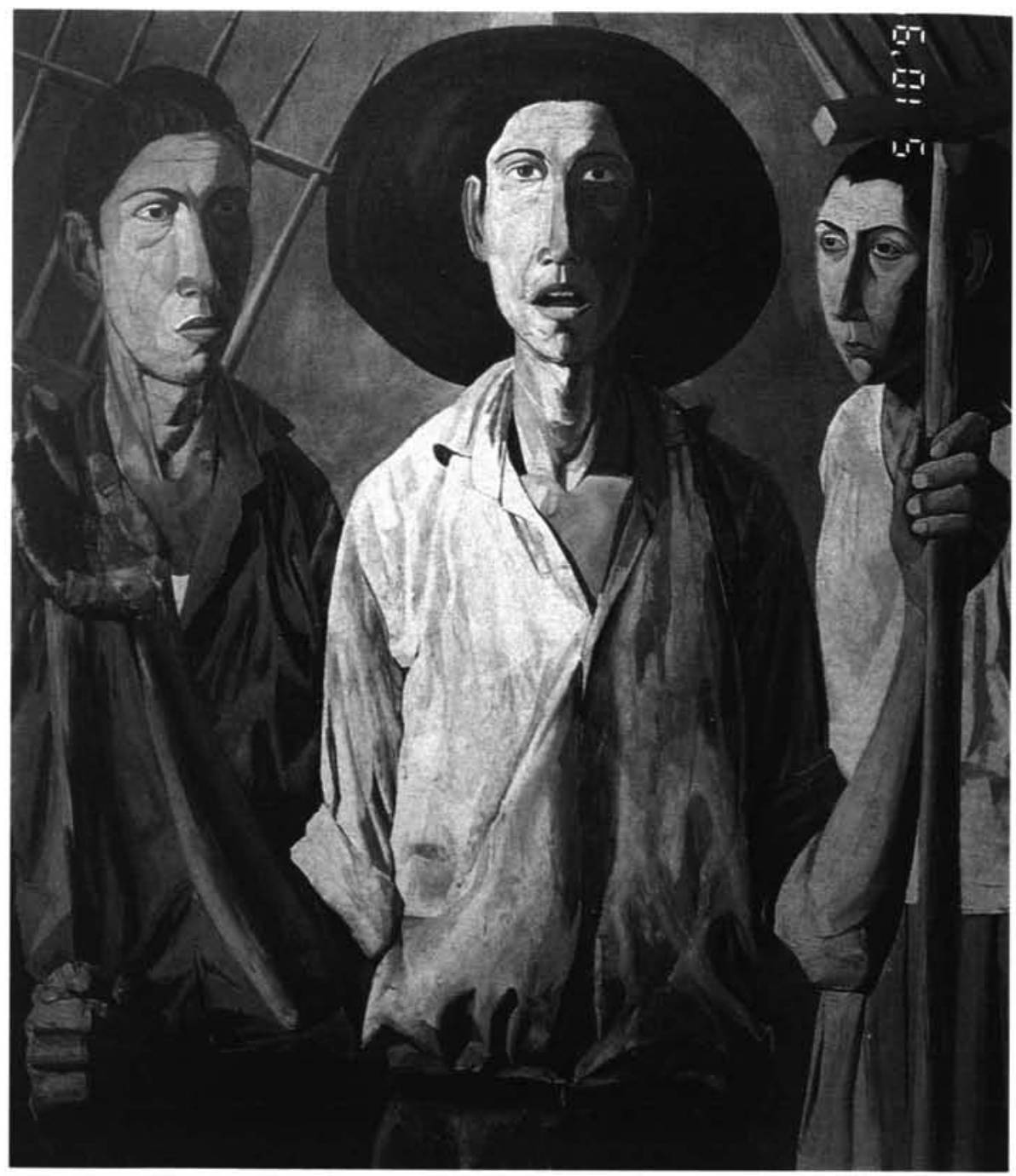

Fig. 2: Pan y Trabajo. 1960 . Tabla. $122 \times 140 \mathrm{cms}$. 


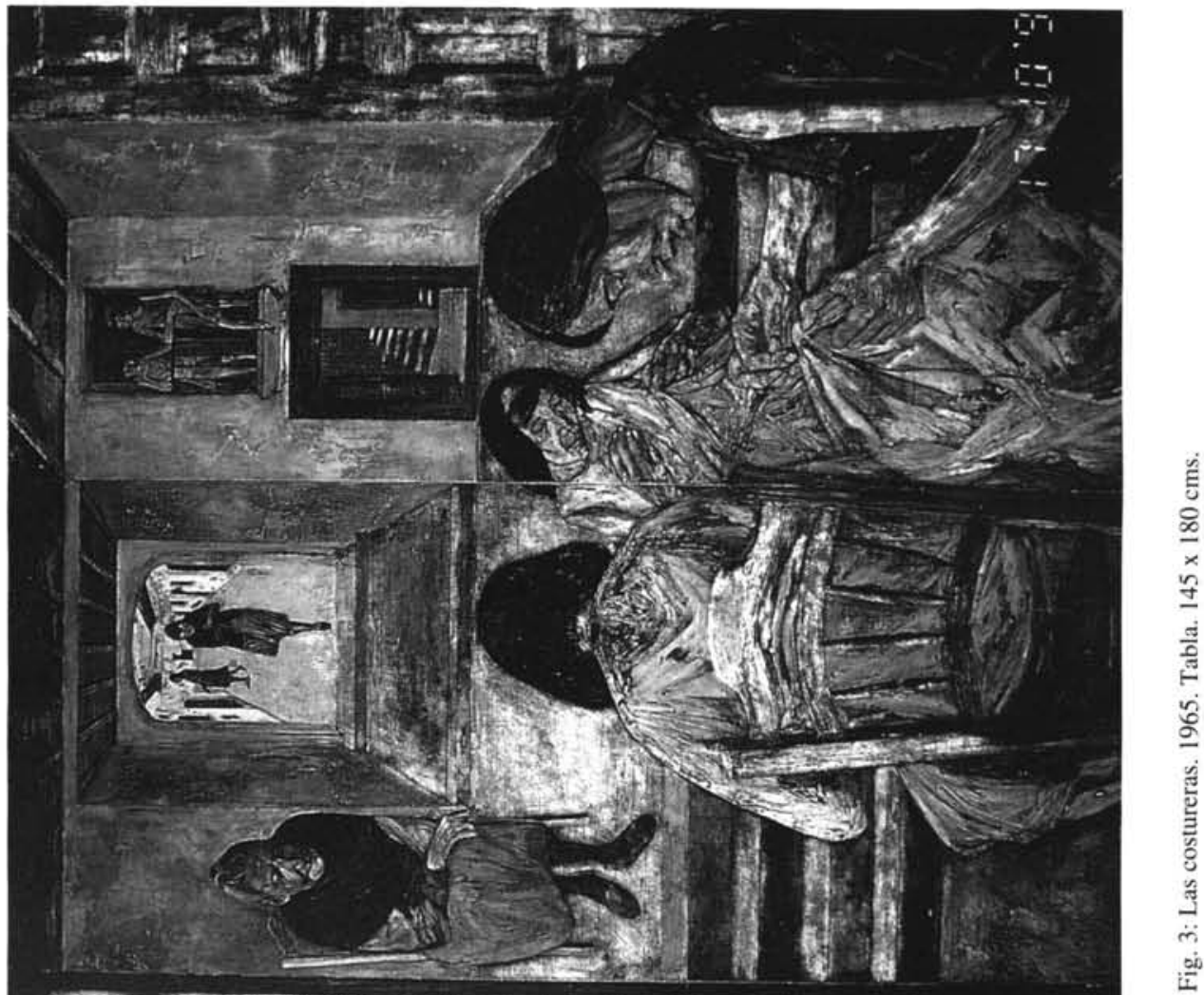

स.

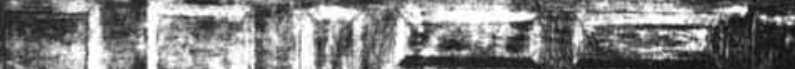

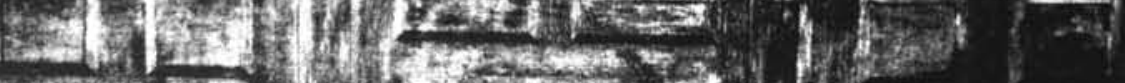

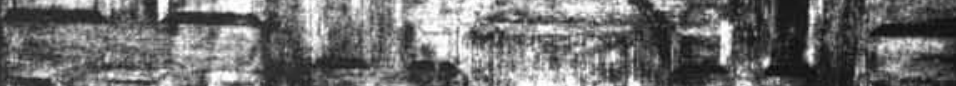

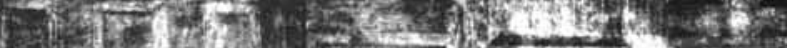

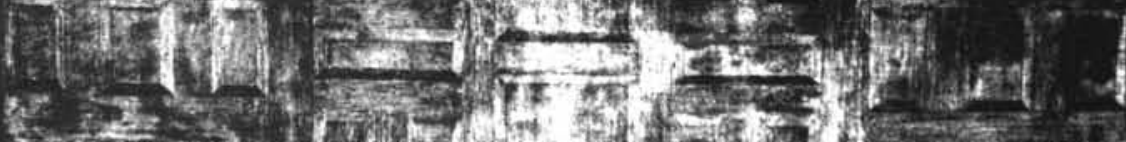

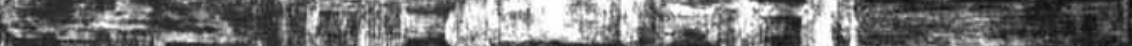

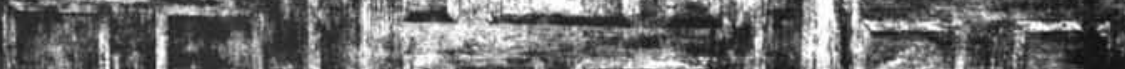

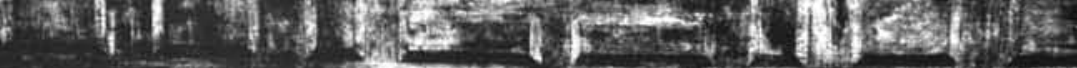




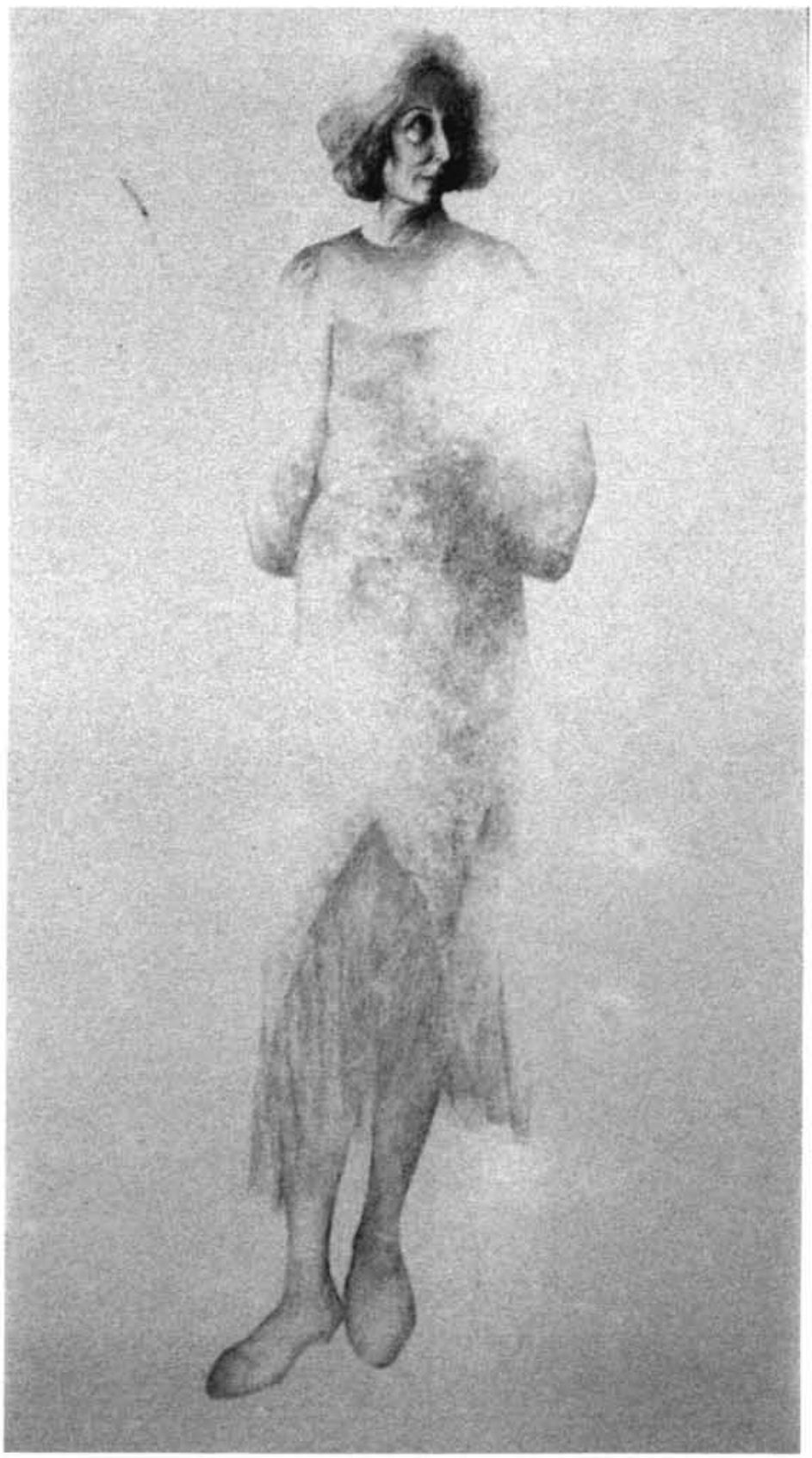

Fig. 4: Marina. 1984. Dibujo a lápiz sobre papel. 50 × $30 \mathrm{cms}$. 


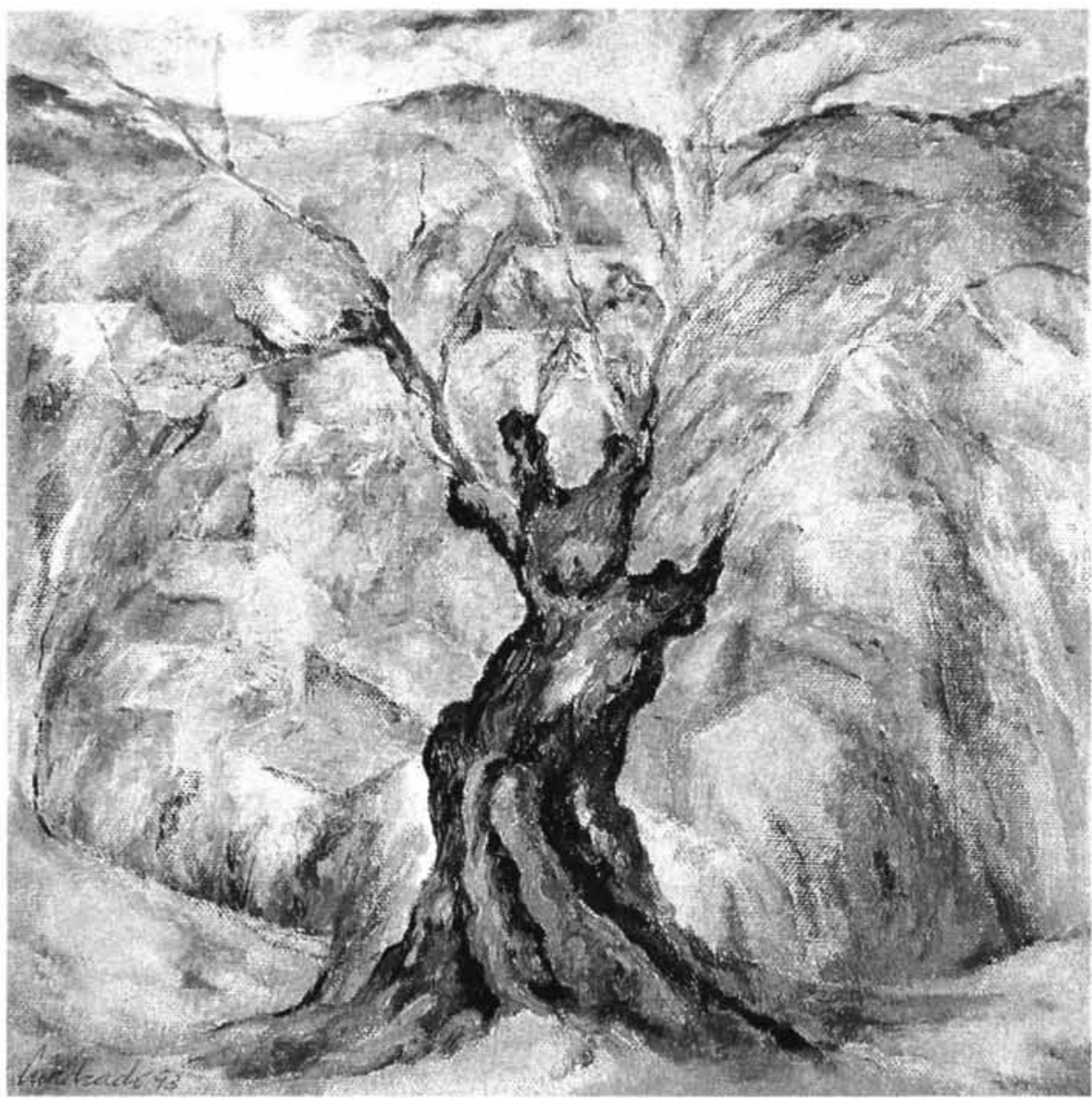

Fig. 5: Fuenteheridos. 1993. Óleo sobre lienzo. 73 x $100 \mathrm{cms}$. 